\title{
Days between Diagnosis and Death
}

National Cancer Institute

\section{Source}

National Cancer Institute. Days between Diagnosis and Death. NCI Thesaurus. Code C156419.

The time interval from a person's date of death to the date of initial pathologic diagnosis, represented as a calculated number of days. 